\title{
El triunfo de Jair M. Bolsonaro Brasil entre el desencanto de la política y el futuro de la democracia
}

\author{
Gisela Pereyra Doval*
}

Cuando un pueblo se desencanta de la política cualquier cosa puede pasar. Cuando uno lo ve de afuera hay muchas situaciones que no se entienden. Y la posverdad (en todas sus aristas) pasa a ser más cierta que la realidad. Sin embargo, es mentira que todo se reduzca al impacto negativo de los medios de comunicación o a la masividad de las fake news. Pensar esto es subestimar al votante.

Para entender el triunfo de Bolsonaro (JMB) en Brasil hay que derribar el mito de que ganó porque los brasileños son fascistas o ignorantes; tampoco responden al modelo del analfabeto político de Bertolt Brecht. Pensar esto de los ciudadanos brasileños es prejuicioso y, en cierta medida, irrespetuoso; aunque entender no implique avalar. Por esto, en primer lugar, ya con el diario del lunes y los resultados de las encuestas, veamos quiénes fueron los votantes de JMB. Podemos pensarlos en dos amplias categorías: la triple B (Bala, Biblia y Buey); y los anti Partido dos Trabalhadores (PT).

Los llamados Bala se engloban en aquellos que están cansados de la inseguridad y de las políticas garantistas de los gobiernos progresistas. También aquellos que creen que "con los militares se estaba mejor". El mismo JMB es un nostálgico de la dictadura que llegó a decir que "el error fue torturar y no matar". Este segmento avala firmemente los proyectos en materia de seguridad que JMB tiene pensados y que veremos más adelante. Sólo para aclarar: esta gente no es "facha"; el año pasado murieron más de 63.000 personas de forma violenta en las grandes urbes brasileñas (hubo aproximadamente un asesinato cada 7 minutos).

El universo Biblia es una masa de electores muy codiciada por los partidos políticos brasileños; representan más del 22\% de la población sumando aproximadamente 43 millones de fieles. El poder de las iglesias evangélicas en Brasil es enorme. Según el Instituto Brasileño de Geografía y Estadística, se abren alrededor 14.000 iglesias evangélicas por año. Esta gente tiene fe en la misión divina que J. Mesías ( !) Bolsonaro se atribuye a él mismo ("Esta misión de Dios no se escoge, se cumple" dijo el día que fue electo); su principal interés es la defensa de las tradiciones en lo que respecta a la Familia, la Nación y los valores cristianos. Bajo el lema "Brasil encima de todo y Dios encima de todos", JMB ha levantado la Biblia como bandera durante toda la campaña electoral. Pero atrás de la fachada mística hay otra realidad: las iglesias ocupan roles sociales cada vez más activos, reemplazando muchas veces al Estado en sus tareas. Como explica Carbonelli (2018), es interesante el rol que el mismo Estado atribuyó a las iglesias como garantes de asignaciones sociales,

\footnotetext{
* Doctora en Relaciones Internacionales, Universidad Nacional de Rosario (UNR, Argentina). Investigadora del Consejo Nacional de Investigaciones Científicas y Tecnológicas (CONICET). Profesora de Problemática de las Relaciones Internacionales, Facultad de Ciencia Política y Relaciones Internacionales (UNR). Email: gpdoval@gmail.com
} 
lo que generó un agenciamiento religioso en el plano de la gestión pública. Tampoco podemos olvidarnos que representantes de las iglesias ocupan desde hace ya varios años lugares de poder repartiéndose en todos los partidos políticos, generando un efecto transversal en la política local y nacional.

Los últimos de la tríada B, corresponden al grupo Buey, que representan los intereses del agrobusiness, lobbistas de los grandes terratenientes. Este grupo no necesariamente simpatiza con JMB sino con su "cerebro económico", Paulo Guedes. Criado en la Escuela de Chicago éste cree firmemente en la reducción del rol del Estado, la liberalización de la economía y la flexibilización de todos los derechos laborales adquiridos y de algunos otros también. Su credo es privatizar para reducir la deuda pública. Sin embargo, como han notado algunos analistas, la puesta en escena de JMB y Guedes desconoce los casi 30 años que el primero votó en el Congreso a favor de medidas estatistas y expansivas; el futuro presidente de Brasil ha tenido un discurso errático en lo que a política económica se refiere.

Last but not least, el grueso de los electores de JMB (30\% según DataFolha) corresponden al grupo anti petista. Para éstos, las crisis institucionales, políticas, económicas y sociales son responsabilidad del PT y sus cuadros corruptos. En este sentido, dos fenómenos pueden resaltarse. Primero, aunque JMB hace 30 años que vive de la política, es percibido como un outsider. En realidad, lo que sale de lo común es el discurso sin filtros del presidente electo, su nuevo partido sin referentes políticos de peso, y que ni él ni los compañeros de su partido están involucrados en la Operaçao Lava Jato (por lo menos no tiene ninguna denuncia).

Segundo y más importante, JMB ganó las elecciones tanto como las perdió el PT. El PT cometió innumerables errores, comenzando por la candidatura de Lula, que tenía la ventaja de movilizar a un electorado que ya tenía cautivo, pero que enfatizaba en la continuidad y no en la renovación, lo que hubiera atraído a otro universo político. La falta de autocrítica también forma parte del proceso: si bien el proceso del departamento de Guarujá es cuanto menos dudoso, y es gráfica la parcialidad del Supremo Tribunal Federal cuya prioridad estuvo puesta más en la proscripción de Lula que en el cumplimiento de la ley - pudiendo hablar de una judicialización de la política, la politización de la justicia, o la justicia como variable de ajuste -, no menos cierto es que sí hubo mucha corrupción en los gobiernos del PT. Sólo reconociendo lo que se hizo mal en las administraciones petistas - lo que no invalida los aciertos - y adueñándose de discursos y temas que la sociedad considera prioritarios, podrá el PT perdurar en la política brasileña. En palabras de Lander, "mientras algunas cosas no se cuestionen, hablar de la crisis política es atenerse a la ceguera".

En este contexto, la cuestión de la inseguridad se constituyó en uno de los pilares de la campaña de JMB. Según las encuestas (el 50\% de los encuestados por Ibope), incluso los votantes del PT coinciden en que hay que tomar medidas para paliar la escalada de violencia que azota las grandes ciudades; con lo cual mucha gente tomó este tema como disparador para votarlo: flexibilizar las leyes y las reglas para la actuación de las fuerzas de seguridad y de la "legítima" defensa. La meta es intimidar o matar a los delincuentes, revirtiendo el aumento de la criminalidad. Varias son las propuestas de ley del nuevo futuro presidente en este sentido: menos límites a la posesión de armas; los crímenes que cometan las fuerzas policiales en ejercicio no serán punibles; ampliación de los delitos tipificados como terrorismo; reducción de la mayoría de edad penal; entre otras. Es todavía un misterio si serán aprobadas por el Congreso o no.

De hecho, la relación entre los distintos poderes del Estado, en particular, y la calidad de la democracia brasileña, en general, también se constituye en una temática de peso en los analistas de lo que será el nuevo gobierno. A pesar de que JMB ha bajado el tono de sus declaraciones a medida que se acercaban las elecciones, planteando que su visión de la democracia había "evolucionado", su llamado en más de una oportunidad a clausurar el Congreso; su desconfíanza en los civiles - plantea 
que su gabinete estará conformado en su mayoría por hombres blancos militares -; el comportamiento de su wanna be vicepresidente, Hamilton Mourao, que ha hablado de la posibilidad de dar un auto-golpe, a partir del cual la corporación militar ayudaría a concentrar el poder en las manos del Ejecutivo, no deja lugar a la imaginación: JMB efectivamente desprecia a la democracia. En este sentido, podemos pensar en que si JMB encuentra resistencia política tenderá a ignorar las prácticas democráticas y las normas. Sin embargo, quizás esto no sea necesario. Los resultados de las elecciones legislativas sugieren que JMB tendrá que lidiar con un Congreso mucho más favorable de lo que se esperaba (su partido tenía un diputado en 2014, a partir de 2016 ocho, y a partir de esta nueva elección serán 52). Otra realidad es que, por lo menos al principio, el presidente electo tendrá un amplio margen de acción. La literatura especializada tiende a enfatizar que, al inicio de un mandato presidencial, a causa de la legitimidad que el voto popular le confiere al candidato, la oposición es menor. Por otra parte, después de la crisis político-institucional que se vivió en los últimos años, la mayoría de los brasileños ve a la democracia como un sinónimo de caos y corrupción. Según una encuesta del Pew Research Center, sólo el 8\% de los entrevistados considera a la democracia una muy buena forma de gobierno. Además, más del $20 \%$ del padrón no fue a votar a pesar de la obligatoriedad - demostrando un gran desencanto con la política -.

Con respecto a la democracia, Bastos Arantes (2018) plantea tres posibles escenarios para gobernar:

1 - Presidencialismo de coalición: en este escenario JMB respetará las reglas de juego de la democracia brasileña tradicional. Sabremos si está dispuesto a evolucionar hacia este escenario si en estos días declara que pretende crear una coalición mayoritaria con diversos partidos políticos, como hicieron todos sus antecesores.

2 - Autoritarismo legal o legalidad autoritaria: se gobierna a través de la fuerza pero siempre buscando algún grado de legitimidad procesal. En Brasil el autoritarismo siempre se presentó como una fuerza modernizante capaz de realizar las reformas que la política democrática era incapaz de enfrentar.

3 - Gobierno errante y movilizado: al volverse un gobierno errante, que busca mantener el apoyo de los electores, pero no consigue doblegar a las instituciones, JMB puede recurrir a la movilización popular directa, con el agravante de que sus elementos aglutinadores, hasta ahora, han sido el odio y la violencia (de la cual él mismo ya fue víctima). En este escenario, puede volcarse a mecanismos de participación directa, como plebiscitos, imaginando que dispone de mayoría social para apoyar sus medidas.

Por último, salvo el perfil del electorado -que ya está comprobado-, estas páginas fueron escritas pensando en hipótesis de trabajo y son bastante provisorias dado el perfil imprevisible que ha mostrado JMB como candidato. Sólo el tiempo dirá cuál de ellas se confirma.

\section{Bibliografía}

BASTOS ARANTES, R. (2018), Tres cenarios para Bolsonaro, Jota. Disponible en: https://www.jota.info/opiniao-e-analise/artigos/tres-cenarios-para-bolsonaro-28102018

CARBONELLI, M. (2018), Entre los templos y las urnas. La gravitación evangélica en la vida política de Brasil, en el Dossier Ele Nao? Las elecciones brasileñas y la coyuntura política, Centro de Estudios en

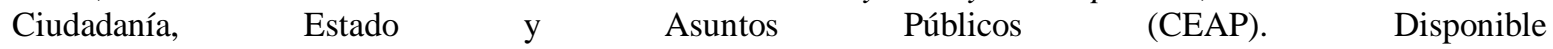
en:http://ceap.sociales.uba.ar/2018/10/16/dossier-ele-nao/ 